\title{
The Importance of Chemical Reactions in the Charging Process of Lithium-Sulfur Batteries
}

\author{
Anne Berger, ${ }^{1, *}$ Anna T. S. Freiberg, ${ }^{1, *}$ Armin Siebel, ${ }^{1, *}$ Rowena Thomas, ${ }^{1}$ \\ Manu U. M. Patel, ${ }^{1}$ Moniek Tromp, ${ }^{2}$ Hubert A. Gasteiger, ${ }^{1, * *}$ and Yelena Gorlin ${ }^{1, * * *, a, z}$ \\ ${ }^{1}$ Chair of Technical Electrochemistry, Department of Chemistry and Catalysis Research Center, Technische Universität \\ München, Garching, Germany \\ ${ }^{2}$ Sustainable Materials Characterisation, Van't Hoff Institute for Molecular Sciences, University of Amsterdam, \\ Amsterdam, Netherlands
}

\begin{abstract}
The underlying mechanism of lithium-sulfur batteries is still not fully established because it involves a series of both chemical and electrochemical reactions as well as the formation of soluble polysulfide intermediates. To improve the mechanistic understanding of lithium-sulfur batteries, this study investigates chemical reactions between the $\mathrm{Li}_{2} \mathrm{~S}$ cathode and more oxidized sulfur species, such as $\mathrm{S}_{8}$ and polysulfides, during the electrochemical charge of the battery. By combining the electrochemistry with X-ray absorption spectroscopy, we show that chemical reactions and, in particular, the resulting accumulation of solution species in the electrolyte are essential to oxidize $\mathrm{Li}_{2} \mathrm{~S}$ at a low overpotential. Additionally, by efficiently separating the anode and cathode compartments of a battery with a lithium ion-exchanged Nafion interlayer, we establish the adverse effect of the anode on the buildup of solution intermediates. In the absence of the interlayer, polysulfide intermediates can diffuse through the separator and react at the anode's surface, while the addition of the interlayer allows the intermediates to accumulate in the separator of the cathode compartment and facilitate the oxidation of $\mathrm{Li}_{2} \mathrm{~S}$.

(C) The Author(s) 2018. Published by ECS. This is an open access article distributed under the terms of the Creative Commons Attribution 4.0 License (CC BY, http://creativecommons.org/licenses/by/4.0/), which permits unrestricted reuse of the work in any medium, provided the original work is properly cited. [DOI: 10.1149/2.0181807jes]

(c))BY
\end{abstract}

Manuscript submitted February 1, 2018; revised manuscript received April 5, 2018. Published May 1, 2018.

The transportation sector is going through a drastic change, as battery powered vehicles gain increasing acceptance. However, the presently used lithium ion ( $\mathrm{Li}$-ion) battery technology may not be sufficient in terms of energy density, cost efficiency, and safety to fulfill the necessary requirements for a widespread utilization of battery electric vehicles (BEVs). ${ }^{1}$ When both the technical and the economic considerations are combined, current projections suggest that BEVs using state-of-the-art Li-ion batteries may not be able to exceed a range of 200 miles for the mid-size car market. ${ }^{2}$ Therefore, research on post $\mathrm{Li}$-ion technologies such as lithium-sulfur ( $\mathrm{Li}-\mathrm{S}$ ) batteries have received increasing attention. As a cathode material, sulfur offers a theoretical gravimetric capacity of $1675 \mathrm{mAh} / \mathrm{g}$, which is 6 times the theoretical gravimetric capacity of NMC (Lithium Nickel Cobalt Manganese Oxide, $278 \mathrm{mAh} / \mathrm{g}$ ), a widely used $\mathrm{Li}$-ion intercalation material for BEVs. ${ }^{3}$ Additionally, sulfur is a promising material as it is abundant, inexpensive and non-toxic. ${ }^{4}$ To date, however, Li-S batteries are far from being commercialized except for niche applications, ${ }^{5}$ as Li-S prototypes can barely compete with state-of-the-art Li-ion technologies. Their high theoretical energy density is decreased by the need of a conductive carbon support to compensate for the insulating nature of sulfur and the volume change during cycling. ${ }^{4}$ Additionally, the realization of a lithium metal anode is problematic due to safety concerns. A recent evaluation estimates that lithium-sulfur batteries might, realistically, not exceed the energy density of lithium-ion batteries but be advantageous in terms of lower cost and reduced environmental impact. $^{2,6}$

Nevertheless, as the commercial realization of Li-S batteries would accelerate the progress in lightweight energy storage, it is important to improve the cell chemistry. Instead of the intercalation mechanism in $\mathrm{Li}$-ion batteries, $\mathrm{Li}-\mathrm{S}$ batteries undergo a conversion reaction to form $\mathrm{Li}_{2} \mathrm{~S}$ during discharge and $\mathrm{S}_{8}$ during charge through a series of both chemical and electrochemical reactions. During the operation of the battery, intermediate polysulfide species dissolve in the electrolyte and diffuse throughout the battery. These soluble intermediates have been held responsible for major drawbacks of the system, most

\footnotetext{
*Electrochemical Society Student Member.

**Electrochemical Society Fellow.

****Electrochemical Society Member

aPresent address: Research and Technology Center, Robert Bosch LLC, California, USA

${ }^{\mathrm{z}}$ E-mail: yelena.gorlin@tum.de
}

prominently the shuttle mechanism. ${ }^{7-9}$ Therefore, many groups are focusing on developing cathode materials that can encapsulate polysulfide species. ${ }^{10-15}$ Extensive research effort is also emerging in the area of mechanistic understanding, as the determination of the exact sequence of steps occurring during the discharge and charge of the battery would help in the design of improved electrode structures and electrolyte solutions.

To increase the mechanistic understanding of Li-S batteries, various research groups have used both electrochemical and spectroscopic techniques, such as X-ray absorption spectroscopy (XAS), ${ }^{16-19}$ X-ray diffraction (XRD), ${ }^{17,20-23}$ and UV/Vis. ${ }^{24,25}$ In general, the studies agree that during the discharge, the voltage curve shows two plateaus at approximately $2.4 \mathrm{~V}$ and at $2.1 \mathrm{~V}$ vs. lithium metal, which are connected by a transition zone. Shen et al. link the upper plateau to the reduction of sulfur to $\mathrm{S}_{8}{ }^{2-}$ and the transition zone to the reduction of $\mathrm{S}_{8}{ }^{2-}$ to lower order polysulfides. The lower plateau is attributed to the formation of $\mathrm{Li}_{2} \mathrm{~S} .{ }^{26}$ The idea of successive reduction steps is supported by Cañas et al., who were able to distinguish via XRD the phase change from crystalline $S_{8}$ to crystalline $\mathrm{Li}_{2} \mathrm{~S}$ via a non-crystalline phase, which they attribute to a formation of soluble polysulfides. ${ }^{21}$ In addition to this stepwise approach, many groups are also including multiple disproportionation reactions in their proposed mechanisms. ${ }^{27-29}$ One of the first to stress this necessity were Lu et al. In their study, the authors employed a two-compartment cell, in which the cathode and anode compartments were separated by a glass membrane and a small concentration of $S_{8}$ was dissolved in the electrolyte of the cathode compartment. In this setup, the theoretical number of 16 electrons per $\mathrm{S}_{8}$ could be extracted at low but not high current rates, which was rationalized through the inclusion of chain-growth and disproportionation steps in the $\mathrm{S}_{8}$ reduction mechanism. ${ }^{27}$

Although most studies assume that the charging pathway is similar to the reverse of the discharging steps, ${ }^{21}$ certain differences are recognized. Most prominently, in contrast to the two plateaus observed during the discharge, only one charging plateau is often seen in the most common electrolyte based on a 1:1 vol:vol mixture of 1,3-dioxolane (DOL) and 1,2-dimethoxyethane (DME). ${ }^{30}$ Marinescu et al. attributed the observation of one single charging plateau to the limiting dissolution of $\mathrm{Li}_{2} \mathrm{~S}^{31} \mathrm{~A}$ similar mechanism is supported by Gorlin et al. who have proposed that $\mathrm{Li}_{2} \mathrm{~S}$ reacts chemically to form polysulfide species, which are subsequently electrochemically oxidized directly to $S_{8}{ }^{32}$ Alternatively, Yang et al. and Cuisinier et al. have proposed that the charging mechanism involves 
several electrochemical reactions and therefore, several charging voltage plateaus. ${ }^{19,33}$

Most proposed discharge and charge mechanisms include both electrochemical and chemical steps, but only few stress the importance of the chemical reactions to the operation of Li-S batteries. We believe that the chemical reactions are especially important during the charge, a process that requires oxidation of insulating and insoluble $\mathrm{Li}_{2} \mathrm{~S}$. In the following study we create conditions, which facilitate chemical reactions between $\mathrm{Li}_{2} \mathrm{~S}$ and solution species, by either adding an $\mathrm{S}_{8}$ containing layer or a polysulfide containing catholyte to a Li-S battery assembled in a discharged state. Furthermore, we apply a lithium ion-exchanged Nafion interlayer to isolate the chemical reactions occurring at the cathode from those occurring at the anode. ${ }^{34}$ These experimental conditions reveal the crucial influence of solution species and the resulting chemical processes to the electrochemical behavior of a Li-S battery.

Although this work focuses on the charging process, the commonly used terminology for the discharging sequence is used, which designates the lithium electrode as the anode and the sulfur-containing electrode as the cathode.

\section{Experimental}

Electrode preparation.- $-L i_{2} S$-electrodes.-The electrodes were prepared inside an argon-filled glove box (MBraun; < 1 ppm $\mathrm{H}_{2} \mathrm{O}$ and $<1$ ppm $\mathrm{O}_{2}$ ) by weighing $\mathrm{Li}_{2} \mathrm{~S}$ powder $(99.98 \%$ trace metal basis, Sigma-Aldrich), Vulcan carbon (XC-72, Tanaka Kikinzoku Kogyo) and polyvinylidene difluoride (PVDF, HSV900, Kynar) in a weight ratio of $6: 3: 1$. The PVDF powder was dissolved in N-Methyl2-pyrrolidone (NMP, anhydrous, $99.5 \%$, Sigma-Aldrich) giving a solution of $25 \mathrm{mg}_{\mathrm{PVDF}}$ per $\mathrm{mL}_{\mathrm{NMP}}$. The slurry was mixed in a sealed container using a planetary centrifugal vacuum mixer (Thinky). At first, only carbon and $\mathrm{Li}_{2} \mathrm{~S}$ were mixed together, and later PVDF dissolved in NMP was added in successive steps. The resulting slurry was coated on $18 \mu \mathrm{m}$ thick aluminum foil using a $250 \mu \mathrm{m}$ gap bar. The coating was dried overnight inside the glove box. The resulting loading was $1.5 \mathrm{mg}_{\mathrm{Li} 2 \mathrm{~S}} / \mathrm{cm}^{2}$. The electrodes were punched using a square punch of the dimensions of $10 \mathrm{~mm}$. Afterwards, they were dried under dynamic vacuum in a glass oven (Büchi, Switzerland) at $110^{\circ} \mathrm{C}$ for 10 hours. The entire procedure was performed inside the glove box or in tightly sealed vessels, preventing all contact with air.

$S_{8}$-interlayer-An $\mathrm{S}_{8} /$ Vulcan carbon composite was synthesized following a previously published procedure. ${ }^{18,35}$ First, $1.5 \mathrm{~g}$ Vulcan carbon (XC-72, Tanaka Kikinzoku Kogyo) was dispersed in $120 \mathrm{~mL}$ of a $1 \mathrm{M}$ sodium thiosulfate solution $\left(\mathrm{Na}_{2} \mathrm{~S}_{2} \mathrm{O}_{3} \cdot 5 \mathrm{H}_{2} \mathrm{O}, 99.5 \%\right.$, SigmaAldrich) for 20 minutes using a high-power sonifier. Then, $250 \mathrm{~mL}$ of $1 \mathrm{M}$ nitric acid $\left(\mathrm{HNO}_{3}, \mathrm{ACS}\right.$ reagent, Sigma-Aldrich) was added to this solution, and the mixture was sonicated for 20 minutes. In the final step, the suspension was washed several times, and the composite was obtained via filtration. Prior to its use in the coating, the composite was dried overnight under ambient conditions and further dried in a glass oven (Büchi, Switzerland) at $80^{\circ} \mathrm{C}$ for 72 hours. The sulfur content was measured via thermogravimetric analysis (Mettler Toledo) to be $68 \%$ by weight.

The sulfur interlayers were prepared by mixing the composite with PVDF at a 9:1 weight ratio. In a sequential way, NMP was added to give a ratio of $7 \mathrm{~mL} \mathrm{NMP} / \mathrm{g}_{\text {Powder }}$. The slurry was coated onto a polyolefin separator (Celgard H2013) and the electrodes were punched in the required dimension of a square of $10 \mathrm{~mm}$. The electrodes were dried over silica gel at $60^{\circ} \mathrm{C}$ and static vacuum in a sealed glass oven. The resulting loading was $2.5 \mathrm{mg}_{\mathrm{S}} / \mathrm{cm}^{2}$.

Ion exchange of Nafion membrane.-Nafion HP membrane (Ion Power) was ion exchanged by sequentially boiling membrane sheets in several solutions. To activate the acid groups, the sheets were boiled in $1 \mathrm{M} \mathrm{HNO}_{3}$ (ACS reagent, Sigma-Aldrich) for 3 hours. Afterwards, the membrane sheets were washed and boiled for another 30 minutes in deionized water. Then, a saturated lithium hydroxide $(\mathrm{LiOH})$ solution was prepared $\left(130 \mathrm{~g}_{\mathrm{LiOH}} / \mathrm{L}\right)$ and the membranes were set to boil in a polypropylene beaker in this solution for another 6 hours. As a final step, the membranes were washed in warm deionized water, dried overnight, and cut into appropriate dimensions $(12 \mathrm{~mm} \times 14 \mathrm{~mm})$. Prior to use in the battery, the membranes were dried under dynamic vacuum in a glass oven (Büchi, Switzerland) at $130^{\circ} \mathrm{C}$ for an additional 10 hours. The resulting lithiated Nafion membranes will be referred to as $\mathrm{Li}^{+}$-Nafion.

Cell assembly and cycling.-For all experiments, our custom-built cell design, ${ }^{18}$ which is compatible with X-ray absorption spectroscopy (XAS) measurements, was used. A lithium metal foil (99.9\% purity, $450 \mu \mathrm{m}$, Rockwood Lithium, USA) served as the anode. Anode and cathode were separated by one layer of a $260 \mu \mathrm{m}$ thick glass-fiber separator (GF, glass microfiber filter 691, VWR) of the dimensions of $11 \mathrm{~mm} \times 13 \mathrm{~mm}$. The separator was soaked with $80 \mu \mathrm{L}$ of electrolyte. Unless stated otherwise, the electrolyte was a mixture of 1,3-dioxolane (DOL, anhydrous, 99.8\%, Sigma-Aldrich) and 1,2-dimethoxyethane (DME, anhydrous, 99.8\%, Sigma-Aldrich) (1:1 vol:vol) with the addition of $1 \mathrm{M}$ lithium perchlorate $\left(\mathrm{LiClO}_{4}\right.$, battery grade, $99.99 \%$ trace metal basis, Sigma-Aldrich) and 0.5 M lithium nitrate $\left(\mathrm{LiNO}_{3}, 99.99 \%\right.$ trace metal basis, Sigma-Aldrich). The same amount of $\mathrm{LiNO}_{3}$ was used in all of the experiments to facilitate proper formation of a solidelectrolyte-interphase layer on the lithium metal. ${ }^{36}$ The solvents were dried for at least 72 hours over Sylobead MS $564 \mathrm{C}$ zeolites $(3 \AA$, Grace Division). $\mathrm{LiClO}_{4}$ and $\mathrm{LiNO}_{3}$ powders were dried at $150^{\circ} \mathrm{C}$ under dynamic vacuum for 72 hours. For the experiments with the $S_{8}$ interlayer, an additional $40 \mu \mathrm{L}$ of electrolyte was added. In the experiments that used $\mathrm{Li}^{+}$-Nafion, one separator was applied on either side of the membrane and $80 \mu \mathrm{L}$ of electrolyte was added to each separator

$\mathrm{Li}_{2} \mathrm{~S}_{8}$ and $\mathrm{Li}_{2} \mathrm{~S}_{4}$ solutions were prepared by adding $\mathrm{Li}_{2} \mathrm{~S}$ and $\mathrm{S}_{8}$ powders in a stoichiometric amount to give the nominal polysulfide composition in DOL:DME (1:1 vol:vol). The desired polysulfide concentration was achieved by varying the volume of the solution. $\mathrm{S}_{8}$ powder (Sigma Aldrich, 99.98\%) was dried under ambient conditions at $75^{\circ} \mathrm{C}$ overnight and $\mathrm{Li}_{2} \mathrm{~S}$ powder was used as received (SigmaAldrich, $99.98 \%$ trace metal basis). The solutions were stirred and heated to $60^{\circ} \mathrm{C}$ to achieve a complete dissolution.

The assembled cells were connected to a potentiostat (Bio-Logic SAS, France) and cycled in a climatic chamber at $25^{\circ} \mathrm{C}$. The time between cell assembly and the start of the electrochemical experiments was $0.5-1$ hour, unless stated otherwise. The current for the galvanostatic charge of the cell was set to a C-rate, ranging from $\mathrm{C} / 2$ to $\mathrm{C} / 10$, based on a theoretical gravimetric capacity of $1165 \mathrm{mAh} / \mathrm{g}_{\mathrm{Li} 2 \mathrm{~S}}$. The scope of this paper only covers the $1^{\text {st }}$ charging sequence at constant current of an electrode with $\mathrm{Li}_{2} \mathrm{~S}$ as starting material. We note that the primary focus of our work was on isolating the chemical reactions occurring at the $\mathrm{Li}_{2} \mathrm{~S}$ electrode from those occurring at the anode through the introduction of ion-exchanged Nafion interlayer. For this purpose, all our experiments utilized the same electrolyte (added in excess); our experiments, however, did not investigate the role of the type of electrolyte solvent or salt, the role of used salt concentration, or the role of used electrolyte to active material ratio.

X-ray absorption spectroscopy measurements.-Sulfur K-edge XAS measurements were performed at the PHOENIX beamline of the Swiss Light Source (SLS, Paul Scherrer Institut, Villigen, Switzerland) and at beamline 14-3 of the Stanford Synchrotron Radiation Lightsource (SSRL). At the SLS, the optimal setup for operando measurements with $\mathrm{Li}^{+}$-Nafion was determined, while the actual spectra included in this paper were taken at the SSRL. Beamline 14-3 is a bending magnet station capable of an energy range between 2100 and $5000 \mathrm{eV}$. The samples were placed inside a holder on a Newport sample station with a submicron positioning accuracy. Measurements were carried out under a helium atmosphere and the spectra were recorded with a Vortex silicon drift detector. The spot size was focused to $15 \mu \mathrm{m}$ in one direction (perpendicular to the cell stack) and 
defocused to $200 \mu \mathrm{m}$ in the other direction. An $8 \mu \mathrm{m}$ Kapton foil (Multek) aluminized with a $100 \mathrm{~nm}$ layer served as an X-ray window. X-ray absorption fluorescence mapping was used to visualize and verify the operando cell alignment. The details of the measurement have been described previously. ${ }^{37}$ In short, fluorescence measurements were performed by fixing the energy of the incident X-rays to $2500 \mathrm{eV}$ and rastering the irradiated spot across a defined area by moving the sample stage in $20 \mu \mathrm{m}$ increments. The location of sulfur was detected by setting the region of interest (ROI) on the detector to $2220-2470 \mathrm{eV}$. After verifying cell alignment, operando X-ray absorption spectroscopy measurements were performed. The step size for X-ray absorption spectra was $0.2 \mathrm{eV}$ in the region of interest between 2460-2500 eV. To allow for better normalization an additional $36 \mathrm{eV}$ were scanned with a step size of $2 \mathrm{eV}$. This protocol led to a data acquisition time of 9 minutes for one spectrum. For operando experiments, the spectra were recorded continuously, alternating between the electrode and the separator locations. The collected data were divided by the intensity of the incoming X-rays to obtain raw spectra, in which the edge step provides a measure of the relative concentration of sulfur species. When necessary, the spectra were also normalized to an edge step of 1 using the Athena software package. The energy scale was calibrated to the peak position of an $\mathrm{S}_{8}$ reference spectrum at $2472 \mathrm{eV}^{38}$ As in our previous work, we present the raw spectra when the focus is on monitoring the relative concentration of sulfur species, and normalized spectra when the focus is on identifying the type of sulfur species. ${ }^{32}$

In addition to fluorescence mapping, the spatial resolution was made certain by measuring an XAS spectrum at the locations of the electrode, the separator, and $\mathrm{Li}^{+}-\mathrm{Nafion}$ (if $\mathrm{Li}^{+}-\mathrm{Nafion}$ was applied to the cell of interest). The electrode location is expected to show a characteristic $\mathrm{Li}_{2} \mathrm{~S}$ signal with a high edge height intensity, whereas the separator location is not expected to show a signal in the sulfur absorption edge, because the starting material, $\mathrm{Li}_{2} \mathrm{~S}$, is not soluble in the electrolyte. The lithiated membrane served as an additional point to verify cell alignment, as the $\mathrm{SO}_{3}{ }^{-}$end groups could also be detected in the studied energy range.

$\mathrm{A} \mathrm{Li}_{2} \mathrm{~S}$ reference was measured by preparing an ex-situ sample of one fabricated $\mathrm{Li}_{2} \mathrm{~S}$ electrode facing the aluminized Kapton window. An $\mathrm{S}_{8}$ reference was measured using the synthesized $\mathrm{S}_{8}$ /Vulcan carbon composite diluted with additional Vulcan carbon to $0.05 \mathrm{wt}-\%$ of $\mathrm{S}_{8}$ to minimize self-absorption. As a representative of a polysulfide reference, a mixture of $\mathrm{Li}_{2} \mathrm{~S}$ and $\mathrm{S}_{8}$ powders to give a $50 \mathrm{mM} \mathrm{Li} \mathrm{S}_{4}$ solution was added to the DOL:DME based electrolyte. The measured XAS spectra of these three references were used to qualitatively analyze the X-ray absorption spectra obtained during operando studies. Quantitative analysis of the spectra was not possible due to the presence of self-absorption effects at sulfur concentrations above $30 \mathrm{mM}$ $\left(30 \mathrm{mM} \mathrm{S}=3.75 \mathrm{mM} \mathrm{S}_{8}\right){ }^{18,39}$

\section{Results and Discussion}

In a recent mechanistic study of Li-S batteries, Gorlin et al. have demonstrated that the overall amount of sulfur containing species $\left(\mathrm{S}_{8}\right.$ and polysulfides) in the separator phase is significantly lower during the first charge of $\mathrm{Li}_{2} \mathrm{~S}$ than in the subsequent discharge and charge processes. $^{32}$ This observation is visualized in Fig. 1, which shows the voltage curve in panel a) and the raw absorption at an energy representing the edge height at $2487.3 \mathrm{eV}$ in panel b). The signal at this energy is proportional to the total amount of S-atoms present (dissolved $\mathrm{S}_{8}$ and $\mathrm{S}_{\mathrm{x}}{ }^{2-}$ ) in the electrolyte. During the first charge, the concentration of sulfur containing species noticeably increases within $50 \%$ of the charge but only to a much lower level compared to subsequent cycles. A single peak at the $\mathrm{S}_{8}$-characteristic energy of $2472 \mathrm{eV}$ is seen in the X-ray absorption spectrum taken after approximately $40 \%$ of the $1^{\text {st }}$ charge (Fig. 1c, blue line). The sole peak indicates that only $S_{8}$ species and not polysulfides are present in the electrolyte. Once the first discharge begins, the concentration of sulfur containing species increases dramatically (Fig. 1b), and the same high amount of sulfur containing species is observed in the a)

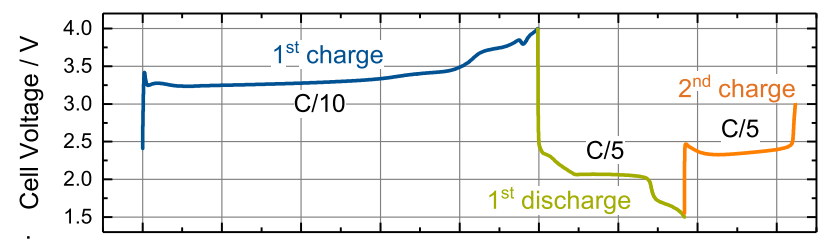

b)

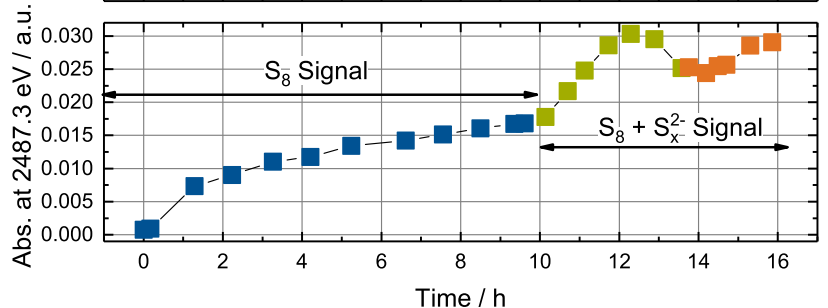

c)

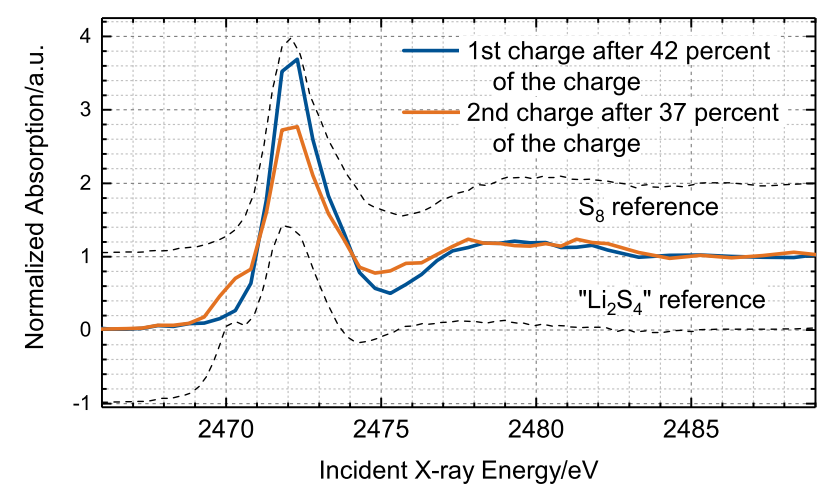

Figure 1. a) Voltage curve over time for $\mathrm{C} / 10$ charge (blue) of an $\mathrm{Li}_{2} \mathrm{~S}$ cathode as starting material followed by a $\mathrm{C} / 5$ discharge (green) and subsequent second charge (orange); b) raw absorption intensity at $2487.3 \mathrm{eV}$ in arbitrary units over time for the sequences described in a), showing the correlation between the low level of sulfur species in the electrolyte and the overpotential of the first charge; c) two representative normalized spectra, which were taken in the separator location from the first (blue) and second charge (orange) after approximately $40 \%$ of the overall charge; the dashed lines show two normalized reference spectra: 1. reference solution containing a stoichiometric mixture of $\mathrm{Li}_{2} \mathrm{~S}$ and $\mathrm{S}_{8}$ in DOL:DME to give $\mathrm{Li}_{2} \mathrm{~S}_{4}$ and 2. $\mathrm{S}_{8}$ powder diluted to a concentration of $0.5 \mathrm{wt}-\%$ (upshifted for clarity) [All data in this figure is a representation of the data set published by Gorlin et al. ${ }^{32}$ ].

electrolyte during the second charge. An additional shoulder feature is seen at an energy of $2470.5 \mathrm{eV}$ in the $\mathrm{X}$-ray absorption spectrum taken after about $40 \%$ of the second charge. The appearance of this additional feature indicates that during the second charge, polysulfide species are present in the electrolyte. However, the reason for the lack of $\mathrm{S}_{\mathrm{x}}{ }^{2-}$ species during the first charge of $\mathrm{Li}_{2} \mathrm{~S}$ remains unclear because it is well known that $\mathrm{S}_{8}$ and $\mathrm{Li}_{2} \mathrm{~S}$ undergo a chemical reaction in aprotic electrolytes to form polysulfides. ${ }^{40}$ Consequently, one would expect that in a Li-S battery assembled in a discharged state, $\mathrm{Li}_{2} \mathrm{~S}$ (starting material) and sulfur (reaction product observed by XAS (cf. Fig. 1)) would also react chemically to produce polysulfides. In the following, we present a series of experiments that focus on the chemical reaction between $\mathrm{S}_{8}$ and $\mathrm{Li}_{2} \mathrm{~S}$ and explain its role in the charging mechanism of Li-S batteries.

Chemical reaction between $\mathrm{Li}_{2} \mathrm{~S}$ and $\mathrm{S}_{8}$.-To investigate the chemical reaction between $\mathrm{S}_{8}$ and $\mathrm{Li}_{2} \mathrm{~S}$, our first experiment was designed without the added complexity of the electrochemical environment by omitting the counter electrode. For a chemical process to occur, it is necessary that both compounds are in close contact with each other, which was achieved by adding an $\mathrm{S}_{8} /$ Vulcan-carboncontaining interlayer that was coated on a Celgard-separator into the standard $\mathrm{Li}_{2} \mathrm{~S}$-Li-cell. The two active materials are inserted in a way that they are conductively connected and facing toward each other. The mass-ratio of $\mathrm{Li}_{2} \mathrm{~S}$ present in the electrode and $\mathrm{S}_{8}$ coated onto 

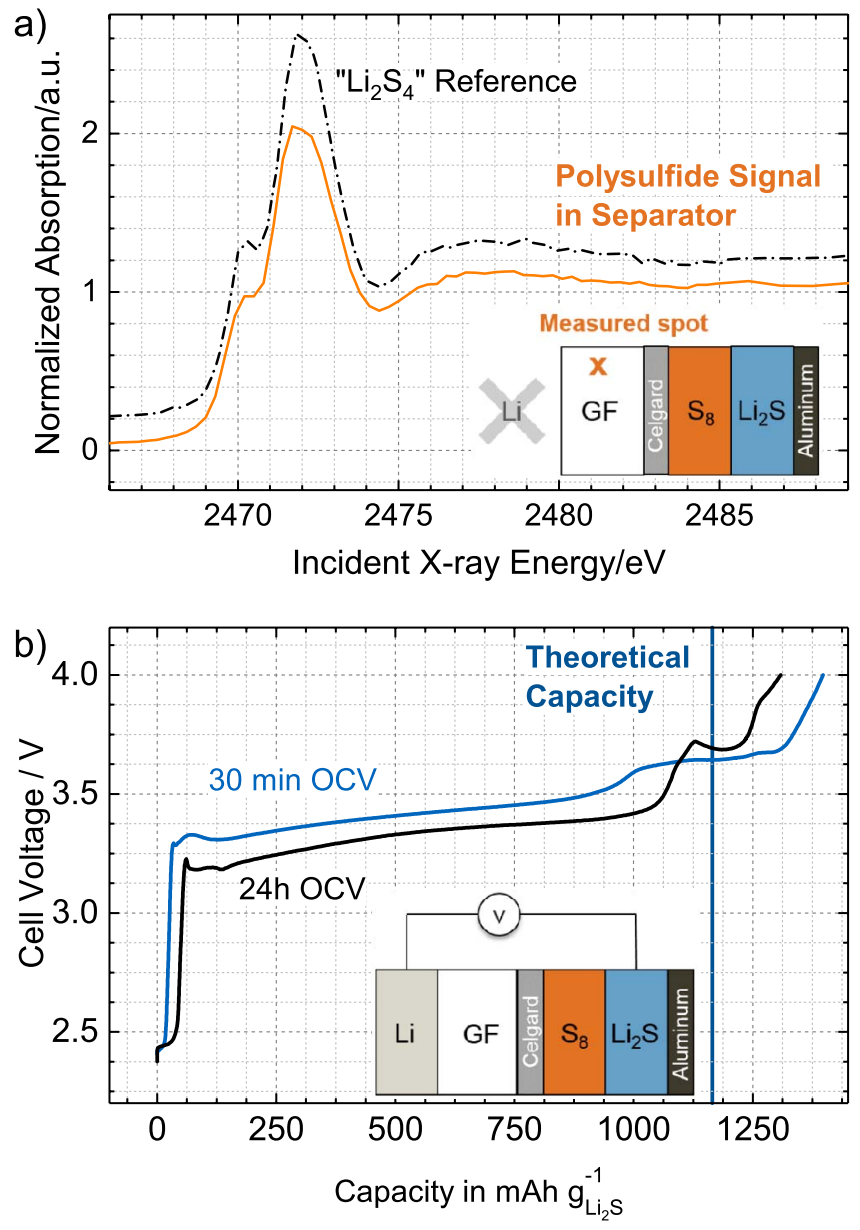

Figure 2. a) Normalized $X$-ray absorption spectrum of the separator spot adjacent to the $\mathrm{S}_{8}$ interlayer in the $\mathrm{Li}_{2} \mathrm{~S}-\mathrm{S}_{\text {interlayer-separator configuration (no }}$ anode); XAS spectra show that the chemical reaction between $\mathrm{S}_{8}$ and $\mathrm{Li}_{2} \mathrm{~S}$ can take place to form polysulfides; the dashed line shows a normalized spectrum of a reference solution for $\mathrm{Li}_{2} \mathrm{~S}_{4}$ (upshifted by 0.2 for clarity); b) voltage curve over the specific capacity for the first charge at a C-rate of C/10 (based on mass of $\mathrm{Li}_{2} \mathrm{~S}$ ) of the $\mathrm{Li}_{2} \mathrm{~S}$ - $\mathrm{Li}$ cell with the $\mathrm{S}_{8}$ containing interlayer (loading $\mathrm{Li}_{2} \mathrm{~S}$ : $1.5 \mathrm{mg}_{\mathrm{Li} 2 \mathrm{~S}} / \mathrm{cm}^{2}, \mathrm{~S}_{8}: 2.5 \mathrm{mg}_{\mathrm{S}} / \mathrm{cm}^{2}$; electrolyte: $1 \mathrm{M} \mathrm{LiClO}_{4}, 0.5 \mathrm{M} \mathrm{LiNO}_{3}$ in DOL:DME, 1:1 vol:vol) after an OCV period of 30 minutes (blue) and 24 hours (black). The vertical blue line marks the theoretical capacity; independent of OCV period, the cell only charges at a potential below $3.0 \mathrm{~V}$ for about $50 \mathrm{mAh} / \mathrm{g}$.

the interlayer is roughly $3: 5$. In contrast to $\mathrm{Li}_{2} \mathrm{~S}$, solid $\mathrm{S}_{8}$ can readily dissolve in the solution and diffuse into the $\mathrm{Li}_{2} \mathrm{~S} / \mathrm{Vulcan}$-carbon structure. Once the $\mathrm{Li}_{2} \mathrm{~S}$ particles and soluble $\mathrm{S}_{8}$ are in direct proximity, a chemical formation of polysulfides is expected and with this presence of polysulfides, an enhancement of the charging process is anticipated.

The described setup without lithium counter electrode $\left(\mathrm{Li}_{2} \mathrm{~S}\right.$ electrode, $\mathrm{S}_{8}$ coating as interlayer, glass fiber separator with electrolyte) was applied in an XAS cell (see inset of Fig. 2a), and XAS was measured in the glass fiber separator location to probe the electrolyte composition. The resulting spectrum, which was taken approximately 1 hour after the cell assembly, can be seen in Fig. 2a. It has two welldefined peaks, one at $2470.5 \mathrm{eV}$ and the other at $2472 \mathrm{eV}$, which are the same two peaks that are present in the polysulfide reference (stoichiometric mixture of $\mathrm{Li}_{2} \mathrm{~S}$ and $\mathrm{S}_{8}$ to give $50 \mathrm{mM} \mathrm{Li}_{2} \mathrm{~S}_{4}$ in DOL:DME) given by the dashed line. Thus, it can clearly be observed that the chemical reaction between $\mathrm{Li}_{2} \mathrm{~S}$ and $\mathrm{S}_{8}$ does occur under the presented condition and that polysulfides are produced in this reaction.

To see if this setup can benefit the $\mathrm{Li}_{2} \mathrm{~S}$ charge, we tested the stacked electrodes versus a lithium metal anode (see inset of Fig. 2b).
As the open circuit voltage (OCV) time might be an important factor regarding dissolution, diffusion, and chemical processes, we tested the cells at two different OCV periods of either 30 minutes or 24 hours. The resulting voltage curves over the specific capacity for a $\mathrm{C} / 10$ charge are shown in Fig. $2 \mathrm{~b}$. Both the current and the mass used to calculate the specific capacity are based on the mass of $\mathrm{Li}_{2} \mathrm{~S}$. The voltage curve reveals that there is only a small initial low plateau for about $35 \mathrm{mAh} / \mathrm{g}_{\mathrm{Li} 2 \mathrm{~S}}$ after 24 hours of OCV, which confirms the results from Fig. 2a: Polysulfides must have formed chemically, and they are responsible for a low charging voltage at the beginning of the process. Their initial presence, however, is not sufficient to maintain the low overpotential throughout a significant portion of the charge. Any further chemical reaction does not lead to a buildup of the polysulfide concentration in the electrolyte. Furthermore, when comparing the black ( $30 \mathrm{~min}$ OCV) and the blue curve ( $24 \mathrm{~h} \mathrm{OCV}$ ), it becomes obvious that there is not a significant difference between both OCV periods, indicating that the time that is given to the system prior to the charge is not the limiting factor.

At the end of the charge, a higher specific capacity is observed than is theoretically expected when only taking the weight of $\mathrm{Li}_{2} \mathrm{~S}$ in the cathode into account. In principle, since $S_{8}$ in the interlayer is in its fully charged state, it should not contribute to the specific capacity of the cell. Nonetheless, it can dissolve in the solution and react with the lithium metal of the anode to produce polysulfides. The formation of these polysulfides adds active material that originated from $\mathrm{S}_{8}$ interlayer and not $\mathrm{Li}_{2} \mathrm{~S}$ electrode and leads to a higher specific capacity than would be expected based purely on the added mass of $\mathrm{Li}_{2} \mathrm{~S}$.

The experiments presented above clearly demonstrate that although $\mathrm{S}_{8}$ and $\mathrm{Li}_{2} \mathrm{~S}$ can react chemically to produce polysulfides (cf. Fig. 2a), the accumulation of polysulfide species is suppressed in an operating battery during the first charge. These observations have led to the hypothesis that the anode must also be interacting with solution species and hindering their concentration buildup during operation. In a typical chemical reaction between $\mathrm{S}_{8}$ and $\mathrm{Li}_{2} \mathrm{~S}$ performed in a vial, the resulting polysulfide intermediates simply accumulate in the aprotic electrolyte. In a $\mathrm{Li}_{2} \mathrm{~S}-\mathrm{Li}$ cell, however, they may diffuse toward and react with the lithium anode, and thus, become unavailable for further chemical reactions with the cathode. Hence, a diffusion barrier suppressing the shuttle process should help maintain an adequate polysulfide concentration and as a consequence allow charging the cell at a low overpotential. The subsequent experiments are aimed at a detailed analysis of this hypothesis.

Influence of the anode.-To separate the cathode compartment from the anode, we have chosen to use a lithiated Nafion membrane ( $\mathrm{Li}^{+}$-Nafion). The negatively charged sulfonate end group $\left(\mathrm{SO}_{3}^{-}\right)$of $\mathrm{Li}^{+}$-Nafion allows $\mathrm{Li}^{+}$-ion transport and stops the diffusion of negatively charged polysulfides. Other than lowering the diffusion coefficient of $\mathrm{S}_{8}$, it does not create an extra electrostatic barrier for the neutral dissolved $\mathrm{S}_{8}$ molecules. The membrane can be implemented in our custom-built spectro-electrochemical cell, leaving all other experimental conditions unchanged.

The voltage profile of the first charge of $\mathrm{Li}_{2} \mathrm{~S}$ at a rate of $\mathrm{C} / 10$ in the presence of the $\mathrm{Li}^{+}$-Nafion is shown in Figure $3 \mathrm{a}$. The charging voltage (black line) is at a low overpotential throughout the entire process, contrasting the results from the cell configuration without the diffusion barrier (blue line), which exhibits a charge at a high overpotential. Because $\mathrm{Li}^{+}$-Nafion stops polysulfide diffusion, we can postulate that the containment of polysulfides at a significant concentration in the cathode compartment is the essential aspect for the improved charging behavior. These polysulfides can react chemically with both $\mathrm{Li}_{2} \mathrm{~S}$ (starting material) and $\mathrm{S}_{8}$ (oxidation product) and thus facilitate the conversion of insulating and insoluble $\mathrm{Li}_{2} \mathrm{~S}$ to solution intermediates that can be subsequently electrochemically oxidized. ${ }^{27}$ The low overpotential in the setup with a diffusion barrier is consistent with recently published data from Wang et al., who utilized an LATP ceramic plate to separate cathode and anode compartments and used commercial micrometer-sized $\mathrm{Li}_{2} \mathrm{~S}$ particles suspended in the 

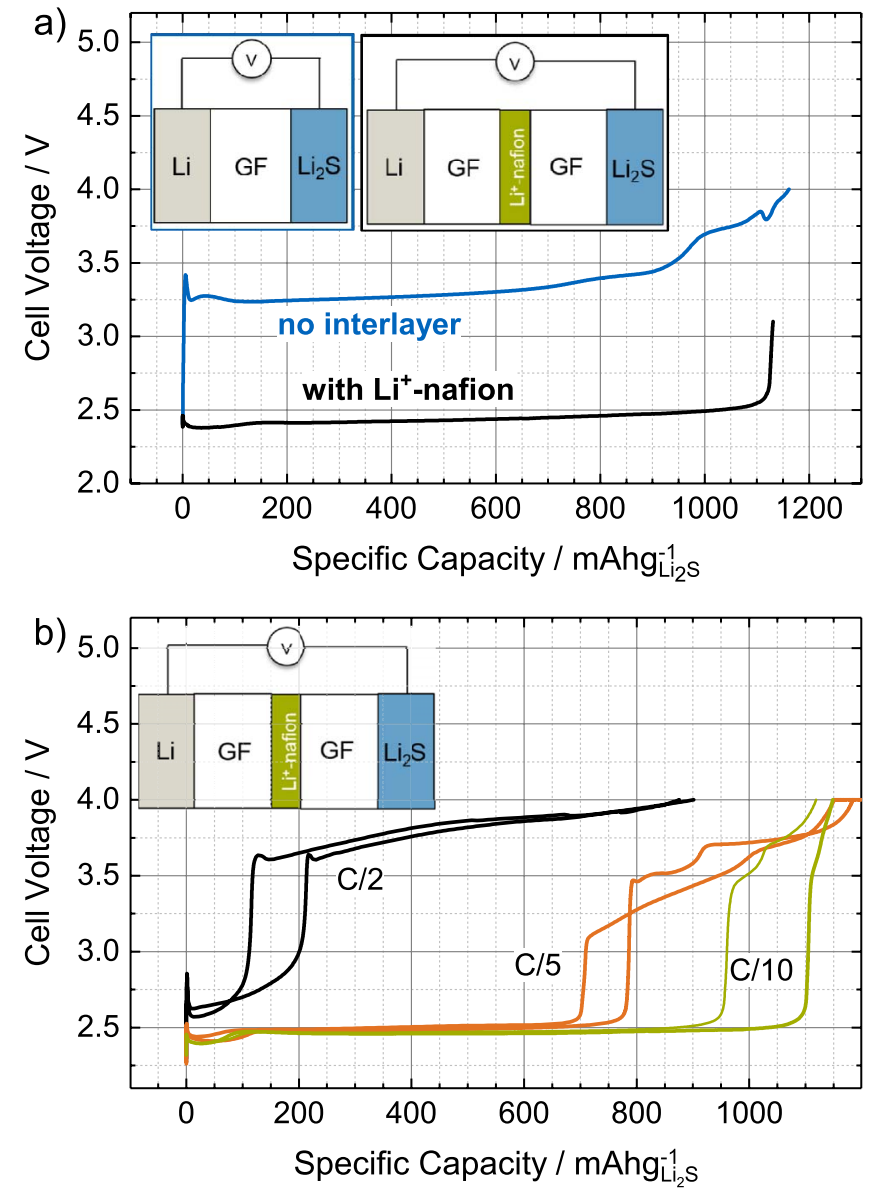

Figure 3. a) Voltage curve over the specific capacity for the first charge of commercial $\mathrm{Li}_{2} \mathrm{~S}$ with $\mathrm{Li}^{+}$-Nafion interlayer (black) showing a charging plateau at $2.4 \mathrm{~V}$ in comparison to the charging curve without the interlayer (blue) showing a charging plateau at a higher voltage of $3.25 \mathrm{~V}$ (loading $\mathrm{Li}_{2} \mathrm{~S}$ : $1.5 \mathrm{mg}_{\mathrm{Li} 2 \mathrm{~S}} / \mathrm{cm}^{2}$, electrolyte: $1 \mathrm{M} \mathrm{LiClO}_{4}, 0.5 \mathrm{M} \mathrm{LiNO}_{3}$ in DOL:DME, $1: 1$ vol:vol); b) voltage curves over the specific capacity for two repetitions of the first charge of $\mathrm{Li}_{2} \mathrm{~S}$ with the $\mathrm{Li}^{+}$-Nafion interlayer for different C-rates: $\mathrm{C} / 2$ (black), C/5 (orange), $\mathrm{C} / 10$ (green); with increasing C-rate the duration of the plateau without overpotential decreases.

electrolyte of the cathode compartment as the active material. ${ }^{41}$ Since the chemical conversion of $\mathrm{Li}_{2} \mathrm{~S}$ to electrochemically active solution intermediates and the electrochemical oxidation of these intermediates occur simultaneously during the charging process, it is necessary for the chemical reactions to be faster than the electrochemical reactions, for the entire charge to occur at a low overpotential. Hence, by varying the rate of the electrochemical reaction via the charging rate, it is possible to explore the kinetics of the chemical reaction. As expected, the charging curves at different rates show a clear dependence of the voltage plateaus on the applied C-rate as shown in Fig. 3 b. While the charging curve at a rate of $\mathrm{C} / 10$ remains at a low potential for most of the charge, faster rates show an earlier sudden increase to a higher potential. Specifically, the low overpotential can be maintained for about half the charge at a rate of $\mathrm{C} / 5$, but, at a rate of $\mathrm{C} / 2$, it is only possible to charge at a low overpotential for a small fraction of the process. These observations indicate that the chemical processes in DOL:DME based electrolyte are relatively slow and become limiting at high current rates. Fig. $3 \mathrm{~b}$ shows two representative repetitions of the experiment to demonstrate the repeatability of the experiment. The slight difference in repetitions is typical to lithium-sulfur batteries and is likely explained either by small differences in how the cells are assembled, which can lead to a different amount of electrolyte present in electrode pores or the separator, or by differences in the length of time between the end of cell assembly and the beginning of the electrochemical experiment. During the OCV time, the electrode is wetted by the electrolyte and any impurities present in $\mathrm{Li}_{2} \mathrm{~S}$ electrode ${ }^{42}$ can react with $\mathrm{Li}_{2} \mathrm{~S}$ resulting in different starting conditions of the cell.

To further investigate the relative concentration and the composition $\left(\mathrm{S}_{8}\right.$ and $\left.\mathrm{S}_{\mathrm{x}}^{2-}\right)$ of sulfur species that form during the charge of $\mathrm{Li}_{2} \mathrm{~S}$ in the presence of $\mathrm{Li}^{+}$-Nafion, we have performed spatially resolved operando XAS measurements at a charging rate of $\mathrm{C} / 5$, where roughly the first half of the charge occurs at a low overpotential and the second half of the charge occurs at a higher overpotential. These experimental conditions have the advantage that the presence or absence of polysulfide species can be probed during one single charging process, which has regions of both high and low overpotentials for a sufficient amount of time. Using our custom-built spectro-electrochemical cell, it was possible to not only characterize species forming in the cathode electrode structure, but also the species that were present in the separator of the cathode compartment. ${ }^{32,43}$

Prior to the operando experiment, the alignment of the cell components at OCV conditions was determined via X-ray fluorescence mapping of the sulfur signal. Fig. 4a shows the obtained fluorescence map of sulfur intensity. The map is positioned next to a schematic representation of cell components. The region with the highest sulfur intensity corresponds to $\mathrm{Li}_{2} \mathrm{~S}$ cathode. Adjacent to the cathode, there is a region with no sulfur content corresponding to the glass fiber separator. Next to the glass fiber separator, another region with significant sulfur intensity can be detected. It corresponds to the $\mathrm{SO}_{3}{ }^{-}$end groups of the $\mathrm{Li}^{+}$-Nafion interlayer. The visualization of the cell alignment allowed us to find appropriate spots for the XAS measurements during the charging process of the cell. In particular, the XAS measurements focused on two spots: $\mathrm{Li}_{2} \mathrm{~S}$ electrode and the separator of the cathode compartment.

The voltage curve collected during the operando experiment is presented in Fig. 4b. As expected, at a C-rate of $\mathrm{C} / 5$ the charging potential remained at $2.5 \mathrm{~V}$ for about $60 \%$ of the charge and then increased to above $3.0 \mathrm{~V}$ for the remaining $40 \%$ of the charge. Throughout the experiment, XAS spectra were continuously measured in the two locations of interest in an alternating sequence. Figs. $4 \mathrm{c}$ and $4 \mathrm{~d}$ present representative spectra corresponding to the initial OCV spectra (i), spectra corresponding to the charging potential of $2.5 \mathrm{~V}$ (ii), spectra corresponding to charging potential of greater than $3.0 \mathrm{~V}$ (iii), and spectra toward the end of the experiment (iv). The exact points of the charge at which the shown spectra were recorded are indicated by triangles in Fig. 4b, with a downward facing triangle corresponding to the spectra taken in the cathode electrode $(\boldsymbol{\nabla})$ and upward facing triangle corresponding to the spectra taken in the cathode separator (ム). The OCV spectrum of the electrode (Fig. 4c, spectrum (i)) shows a clear $\mathrm{Li}_{2} \mathrm{~S}$ characteristic with the two peaks at $2473 \mathrm{eV}$ and $2476 \mathrm{eV}$. As the charge proceeds, the electrode spectrum (Fig. 4c, spectrum (ii)) still shows the presence of $\mathrm{Li}_{2} \mathrm{~S}$, as evidenced by the presence of the second peak at $2476 \mathrm{eV}$, but it also displays a newly developed $\mathrm{S}_{8}$ feature, as evidenced by an increase in absorption intensity of the first peak and its shift from $2473 \mathrm{eV}$ to $2472.5 \mathrm{eV}$. An even stronger $\mathrm{S}_{8}$ signal and a weaker $\mathrm{Li}_{2} \mathrm{~S}$ signal can be detected later in the charge (Fig. 4c, spectrum (iii)), after the charging potential increases above 3.0 V. Towards the end of the charge (Fig. $4 \mathrm{c}$, spectrum (iv)), the first peak has shifted to the characteristic $S_{8}$ energy of $2472 \mathrm{eV}$, indicating a close to complete conversion of $\mathrm{Li}_{2} \mathrm{~S}$ to $\mathrm{S}_{8}$. We note that in addition to the main peak at $2472 \mathrm{eV}$, the last spectrum contains a small shoulder at $2473 \mathrm{eV}$. Although the presence of the shoulder can be interpreted as a remaining feature of $\mathrm{Li}_{2} \mathrm{~S}$, we believe that a major part of the feature is an artifact of self-absorption. In previous XAS studies, the same shoulder feature is present in concentrated sulfur samples that experience self-absorption, but is absent in dilute sulfur samples, in which an undistorted sulfur spectrum is measured. ${ }^{18,44}$

Fig. 4d shows equivalent data for the separator of the cathode compartment. The OCV spectrum at point (i) is omitted because the overall S-signal in the separator is at a very low level at the start of the experiment (as shown later). As the charging process starts at a 

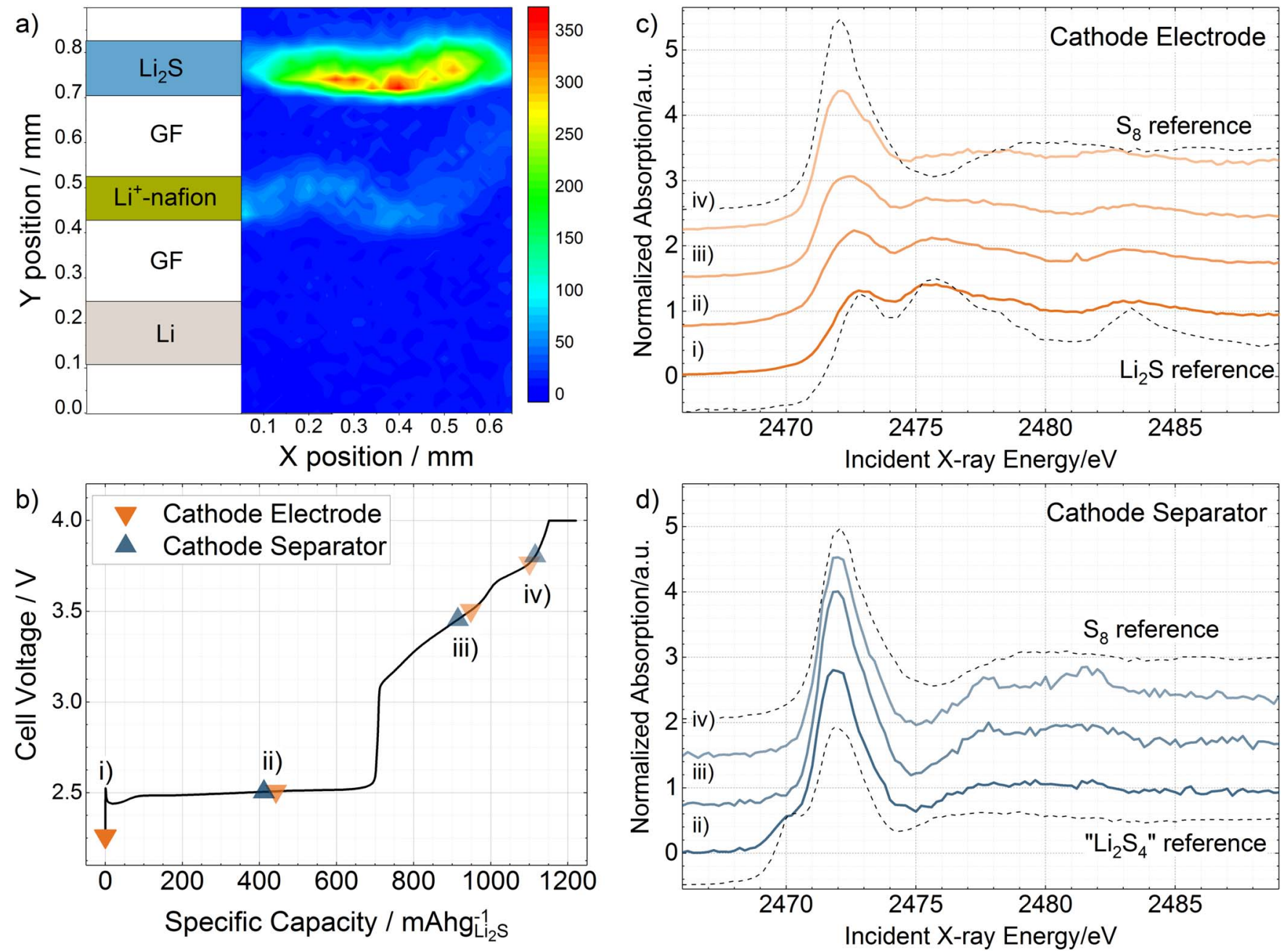

Figure 4. a) X-ray fluorescence map showing the relative sulfur intensity inside the cell; b) voltage curve over the specific capacity of the measured cell at a C-rate of $\mathrm{C} / 5$ with $\mathrm{Li}^{+}$-Nafion interlayer (loading $\mathrm{Li}_{2} \mathrm{~S}: 1.5 \mathrm{mgLi}_{2} \mathrm{~S}_{\mathrm{cm}}{ }^{2}$, electrolyte: $1 \mathrm{M} \mathrm{LiClO}_{4}, 0.5 \mathrm{M} \mathrm{LiNO}_{3}$ in DOL:DME, $1: 1 \mathrm{vol}: \mathrm{vol}$ ). The symbols on the voltage curve signify where ( $\boldsymbol{\nabla}=$ cathode electrode, $\boldsymbol{\Lambda}=$ cathode separator) and when the XAS spectra i)-iv) in c) and d) were taken; c), d) normalized X-ray absorption intensity over the incident X-ray energy from the cathode electrode (c) and cathode separator (d) locations; the spectra are upshifted by 0.75 for clarity. The electrode spectra show a conversion from $\mathrm{Li}_{2} \mathrm{~S}$ to $\mathrm{S}_{8}$, while the separator spectra demonstrate the presence of polysulfides during the charging process at a low overpotential and their absence during the charging process at a high overpotential; panel c) and d) contain reference spectra for $\mathrm{S}, \mathrm{Li}_{2} \mathrm{~S}_{4}$, and $\mathrm{Li}_{2} \mathrm{~S}$ in the dashed lines.

low overpotential, the separator spectrum develops two clear peaks at $2470.5 \mathrm{eV}$ and $2472 \mathrm{eV}$ in the sulfur absorption edge (Fig. 4d, spectrum (ii)), indicating the presence of polysulfide species. ${ }^{16}$ At both points (iii) and (iv) of the charge, where the charging potential exhibits a high overpotential, the characteristic polysulfide feature at $2470.5 \mathrm{eV}$ is not present anymore, indicating that polysulfide species have been depleted. The remaining characteristic $S_{8}$ feature suggests that only sulfur remains in the separator.

To determine how the relative concentration of sulfur species in the separator of the cathode compartment changes throughout the charging process, XAS spectra depicting the raw X-ray absorption (without the normalization to an edge step of 1) are shown in Fig. 5 for the same experiment as that presented in Fig. 4. For clarity, the spectra are presented in two different panels: The spectra recorded during the first $60 \%$ of the charge (charging potential of $2.5 \mathrm{~V}$ ) are shown in Fig. 5a, while the spectra from the remaining $40 \%$ of the charge are presented in Fig. 5b. The first spectrum (a) in Fig. 5a was measured at OCV conditions, and therefore, there was not a significant $\mathrm{S}$-signal detected in that spectrum. Starting with spectrum (b) and continuing until spectrum $(j)$, the overall sulfur signal is continuously increasing, as is evident by a growing edge height (absorption intensity evaluated at $2487.3 \mathrm{eV}$ ). The rise in the overpotential at $700 \mathrm{mAh} / \mathrm{g}_{\mathrm{Li} 2 \mathrm{~S}}$ can be directly correlated with a change in X-ray absorption spectra. In comparison to spectrum (j), spectrum $(\mathrm{k})$, which was measured during the initial rise in the charging potential to above $3.0 \mathrm{~V}$, has both a significantly lower edge height and a significantly smaller signal at $2470.5 \mathrm{eV}$, the characteristic peak energy of polysulfides. As the charge continues above $3.0 \mathrm{~V}$, little change is seen between spectra (l) through (p). To visualize the observed trend better, the raw absorption intensity above the edge at $2487.3 \mathrm{eV}$ is plotted versus capacity in Fig. 5c (orange symbols). From the figure, it is clear that the increase in sulfur intensity ( sum of $\mathrm{S}_{8}$ and $\mathrm{S}_{\mathrm{x}}{ }^{2-}$ ) during the first $60 \%$ of the charge is linear, and that the increase in the charging potential coincides with a drop in the sulfur intensity ( Furthermore, as already discussed in the context of Fig. $4 \mathrm{c}$, the rise in the charging potential to above $3.0 \mathrm{~V}$ can also be correlated to the sudden disappearance of the polysulfide feature. Thus, the obtained operando results in the presence of $\mathrm{Li}^{+}-\mathrm{Nafion}$ are entirely consistent with the observations made in the conventional cell in which solution species can freely diffuse between the cathode and the anode. ${ }^{32}$ In both experimental setups, the charge of $\mathrm{Li}_{2} \mathrm{~S}$ occurs at a high overpotential, when polysulfides are not detected in the separator. When polysulfides 

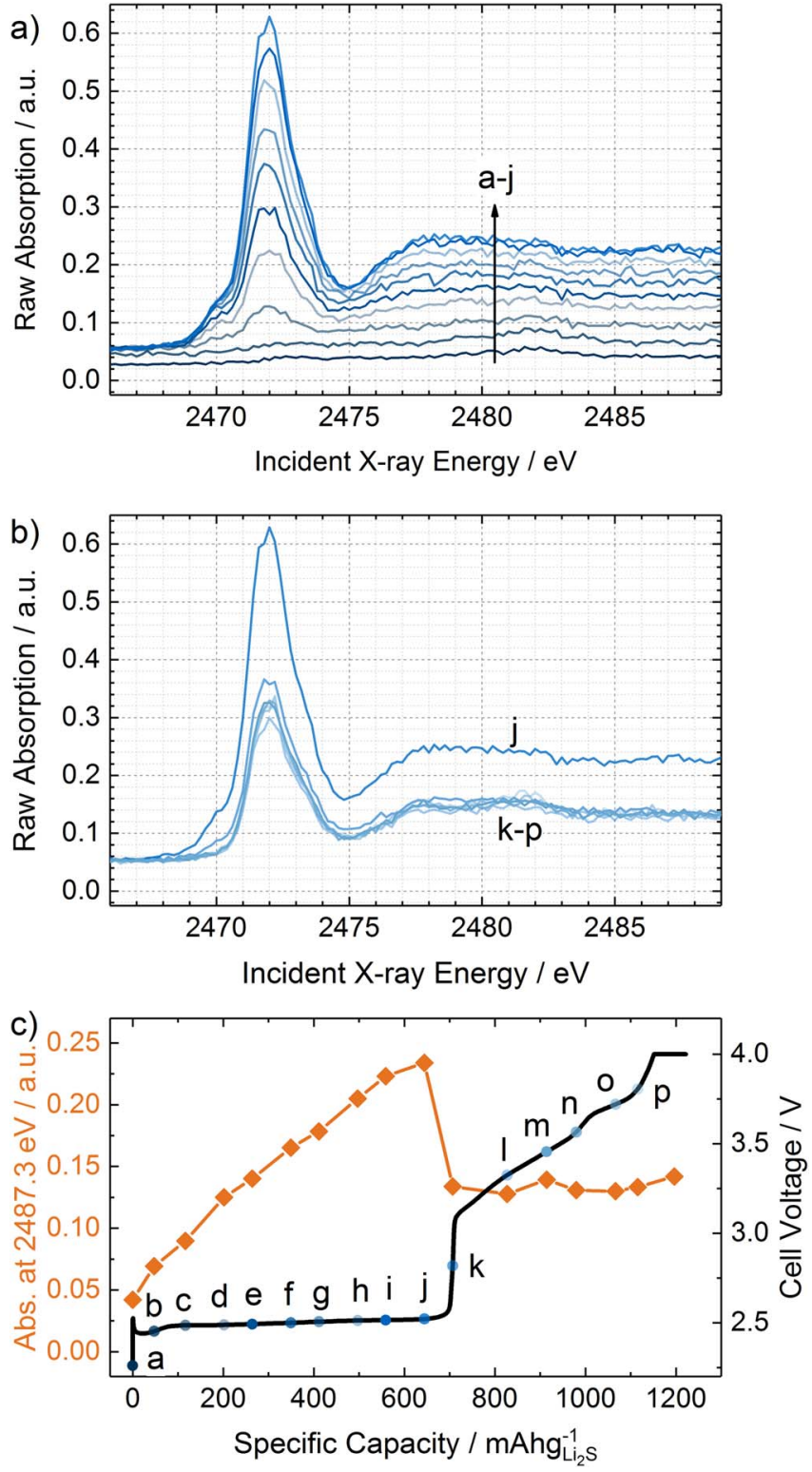

Figure 5. Raw X-ray absorption intensity over the incident X-ray energy of the $\mathrm{Li}^{+}$-Nafion experiment presented in Fig. 4. Panel a) focuses on points $a-j$ and panel $b$ ) on points $j-p$, while $j$ is repeated for comparison; panel $c$ ) depicts the same voltage curve (black line) from Fig. $4 \mathrm{a}$ and visualizes both the portion of the charge at which points a-p were generated (blue circles) and the absorption intensity at $2487.3 \mathrm{eV}$ (measure of sulfur concentration) as a function of specific capacity (orange symbols).

are detected in the separator (the first $60 \%$ of the $\mathrm{C} / 5$ charge in the setup with $\mathrm{Li}^{+}$-Nafion or the second charge in the conventional setup), the charge process occurs at $\approx 2.5 \mathrm{~V}$.

A simple additional electrochemical experiment can further demonstrate the impact of polysulfide intermediates on the charging process. In this experiment, the $\mathrm{Li}^{+}-\mathrm{Nafion}$ is kept in the cell, but the standard electrolyte in the cathode compartment is exchanged with a catholyte containing $50 \mathrm{mM}$ of $\mathrm{Li}_{2} \mathrm{~S}_{8}$ (corresponding to $400 \mathrm{mM}$ of $\mathrm{S}$ ), and the charging rate is increased from $\mathrm{C} / 5$ to $\mathrm{C} / 2$. To estimate the expected contribution of the added polysulfides to the capacity of the first charge, we assume that the separator can only contain a volume of $28 \mu \mathrm{L}$ (volume of separator: $200 \mu \mathrm{m} \times 11 \mathrm{~mm} \times 14 \mathrm{~mm}$; porosity: 0.9 in uncompressed state); if normalized by $\mathrm{Li}_{2} \mathrm{~S}$ loading of $1.5 \mathrm{mg}_{\mathrm{Li} 2 \mathrm{~S}}$ this corresponds to $50 \mathrm{mAh} / \mathrm{g}_{\mathrm{Li} 2 \mathrm{~S}}$, which is negligible
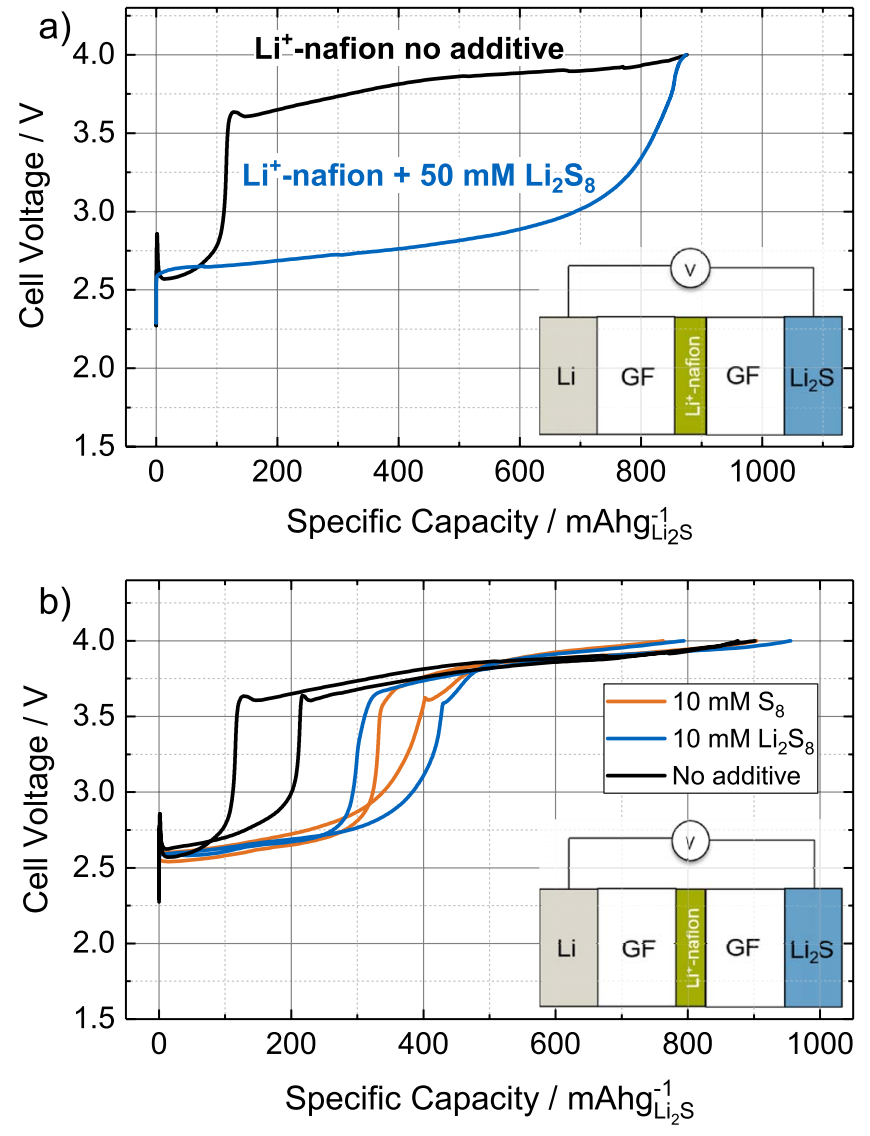

Figure 6. a) Voltage curve over the specific capacity for the first charge of $\mathrm{Li}_{2} \mathrm{~S}$ at a C-rate of $\mathrm{C} / 2$ with $\mathrm{Li}^{+}$-Nafion interlayer (loading $\mathrm{Li}_{2} \mathrm{~S}: 1.5 \mathrm{mg} \mathrm{Li}_{2 \mathrm{~S}} / \mathrm{cm}^{2}$, electrolyte: $1 \mathrm{M} \mathrm{LiClO}_{4}, 0.5 \mathrm{M} \mathrm{LiNO}_{3}$ in DOL:DME, $1: 1$ vol:vol); two cases are shown, with black curve representing the standard case and blue curve representing the case in which $50 \mathrm{mM}$ of $\mathrm{Li}_{2} \mathrm{~S}_{8}$ was added to the cathode compartment. While the chemical processes in the standard case become limiting causing the appearance overpotential, a sufficient polysulfide amount added to the cathode compartment leads to a charging process at a low overpotential; b) voltage curves of the first charge of $\mathrm{Li}_{2} \mathrm{~S}$ with the lithiated Nafion interlayer for different additives (cathode compartment only) with a fixed OCV period of 40 minutes; orange curves represent $10 \mathrm{mM} \mathrm{S}_{8}$, blue curves represent $10 \mathrm{mM} \mathrm{Li}_{2} \mathrm{~S}_{8}$, and black curves represent the control case with no additive; $\mathrm{S}_{8}$ and $\mathrm{Li}_{2} \mathrm{~S}_{8}$ have a similar enhancing effect on the charging process.

compared to the overall charge capacity of $1165 \mathrm{mAh} / \mathrm{gLi}_{2} \mathrm{~S}$. The results of the experiment are shown in Fig. 6a. As seen in the figure, in the presence of a $50 \mathrm{mM}$ of $\mathrm{Li}_{2} \mathrm{~S}_{8}$ solution, a major portion of the charging process can occur at a potential below 3.0 V. In the absence of $50 \mathrm{mM} \mathrm{Li}_{2} \mathrm{~S}_{8}$, however, almost the entire charging process occurs at a potential above $3.0 \mathrm{~V}$ (see Fig. 3b). Due to this improved charging behavior in the latter configuration, the addition of a significant polysulfide concentration and restriction of polysulfides to the cathode compartment can facilitate oxidation of $\mathrm{Li}_{2} \mathrm{~S}$ to $\mathrm{S}_{8}$ at a low overpotential, even at charging rates as high as $\mathrm{C} / 2$. We note that when the same polysulfide concentration is added in the absence of $\mathrm{Li}^{+}$-Nafion, in which case the added polysulfides are not restricted to the cathode compartment, the main portion of the charge at the charging rate of $\mathrm{C} / 2$ proceeds at a potential higher than $3.0 \mathrm{~V}$. This case is illustrated in Fig. A1 of Appendix A.

Comparison of $\mathrm{S}_{8}$ and $\mathrm{Li}_{2} \mathrm{~S}_{8}$ as redox mediators.-It would be interesting to conduct a similar experiment with the addition of $50 \mathrm{mM}$ $\mathrm{S}_{8}$ to evaluate the relative effectiveness of sulfur and polysulfides as redox mediators. In principle, both species can mediate the charging 
process of $\mathrm{Li}_{2} \mathrm{~S}$ by bringing it into solution, as shown by Equations 1 and 2.

$$
\begin{aligned}
& \mathrm{Li}_{2} \mathrm{~S}_{\text {solid }}+\frac{x-1}{8} \mathrm{~S}_{8, \text { solution }} \rightarrow 2 \mathrm{Li}_{\text {solution }}^{+}+\mathrm{S}_{\mathrm{x} \text {,solution }}^{2-} \\
& \mathrm{Li}_{2} \mathrm{~S}_{\text {solid }}+\frac{y-1}{8-y} \mathrm{~S}_{8, \text { solution }}^{2-} \rightarrow 2 \mathrm{Li}_{\text {solution }}^{+}+\frac{7}{8-y} \mathrm{~S}_{y, \text { solution }}^{2-} \\
& 2<y<8
\end{aligned}
$$

Unfortunately, the experiment with $50 \mathrm{mM} \mathrm{S}_{8}$ is not possible in a standard DOL:DME electrolyte, because $S_{8}$ is soluble only up to a concentration of $\approx 10 \mathrm{mM}$ of $S_{8}$ or $\approx 80 \mathrm{mM} \mathrm{S}$. Nonetheless, it is experimentally feasible to add $10 \mathrm{mM}$ of either $\mathrm{S}_{8}$ or $\mathrm{Li}_{2} \mathrm{~S}_{8}$ and compare the relative effectiveness of the two types of sulfur species. Fig. $6 \mathrm{~b}$ shows the electrochemical response after such an addition of the two types of species (total $\mathrm{S}$ concentration equals to $80 \mathrm{mM}$ in both cases). We note that because the added $\mathrm{Li}_{2} \mathrm{~S}_{8}$ is expected to contribute only $10 \mathrm{mAh} / \mathrm{g}_{\mathrm{Li} 2 \mathrm{~S}}$ to the capacity of the first charge (see calculation in the previous section), this contribution can be neglected in the analysis. Experimental data was collected in the cell setup with $\mathrm{Li}^{+}$-Nafion, using $\mathrm{C} / 2$ charge rate based on the weight of $\mathrm{Li}_{2} \mathrm{~S}$ in the cathode, and each experiment was conducted twice to generate duplicate data. The orange curves represent the cells with $10 \mathrm{mM} \mathrm{S}_{8}$, the blue curves represent the cells with $10 \mathrm{mM} \mathrm{Li}_{2} \mathrm{~S}_{8}$, while black curves represent the cells without any additives. The OCV period between each cell assembly and the beginning of the charging process was controlled to be $30-45$ minutes. From the figure, it is seen that similar behavior was observed in the presence of either $\mathrm{Li}_{2} \mathrm{~S}_{8}$ or $\mathrm{S}_{8}$. Specifically, in both cases the portion of the charging process that occurred at a lower overpotential was approximately doubled relative to the control experiment (black lines). This result indicates that both species can equally mediate the charging process, when present in the same concentration. However, since the solubility of $S_{8}$ is significantly lower than that of $\mathrm{Li}_{2} \mathrm{~S}_{8}$, it is less effective as a mediator during the operation of the battery.

Equations 1 and 2 show the chemical reactions that need to occur to bring $\mathrm{Li}_{2} \mathrm{~S}$ particles into solution as polysulfides, thereby facilitating the charging process of Li-S batteries. ${ }^{33,45}$ This dissolution step has already been proposed by Marinescu et al. to be the "bottleneck" of the charge. ${ }^{31}$ They demonstrated via computational studies that the characteristic shape of the charging curve can only be simulated when including a gradual dissolution of $\mathrm{Li}_{2} \mathrm{~S}$. The results of our study provide concrete experimental evidence to their hypothesis, as we show that the charge of $\mathrm{Li}_{2} \mathrm{~S}$ can only proceed with a low overpotential when solution species, which are facilitating the chemical reaction with $\mathrm{Li}_{2} \mathrm{~S}$, are present. Therefore, it can be stated that solution species and, in general, the chemical reactions that are made accessible through these species are essential to a charge at a low overpotential. In this regard we note that if the cell is brought into conditions where the chemical steps are suppressed by either a lack of solution species, by limiting the reaction time, or by competing reactions of solution species at the anode, the charging process requires application of a higher overpotential. Alternatively, if the chemical reactions are facilitated, for example, by decreasing the particle size of the active material and thereby increasing its surface area, then the charging process requires a lower overpotential. This phenomenon has already been demonstrated in a number of studies in literature. ${ }^{33,45,46}$

\section{Conclusions}

In this study, we used a combination of electrochemical and spectroscopic experiments to generate a detailed understanding of chemical processes occurring during the charge of lithium-sulfur batteries. We found that the primary oxidation pathway of $\mathrm{Li}_{2} \mathrm{~S}$ is through a chemical reaction step involving either $\mathrm{S}_{8}$ or $\mathrm{S}_{\mathrm{x}}{ }^{2-}$ to form electrochemically active solution species. These solution species could then be electrochemically oxidized or they could diffuse toward the anode, where they would react with the lithium metal. When this parasitic reaction at the anode was eliminated through an introduction of a polysulfide diffusion layer (e.g. $\mathrm{Li}^{+}$-Nafion interlayer), $\mathrm{Li}_{2} \mathrm{~S}$ could be charged at a low overpotential using a typical charging rate of $\mathrm{C} / 10$. As the rate was increased to $\mathrm{C} / 2$, however, the charge could proceed at a lower overpotential only when a significant concentration of polysulfides $(\approx 50 \mathrm{mM})$ was added to the separator of the cathode compartment. Finally, the relative effectiveness of $S_{8}$ and polysulfides as redox intermediators was evaluated. Although both $S_{8}$ and polysulfides showed similar ability to mediate the charge of $\mathrm{Li}_{2} \mathrm{~S}$ when added at the same concentration of $10 \mathrm{mM}, 10 \mathrm{mM}$ concentration was shown to not be sufficient to allow the charging process to occur at a low overpotential at a charging rate of $\mathrm{C} / 2$. Because the solubility of $S_{8}$ in the DOL:DME electrolyte is limited to only $10 \mathrm{mM}$, this finding clarified why solid $S_{8}$ that continuously forms throughout the charge of $\mathrm{Li}_{2} \mathrm{~S}$ cannot serve as a substitute redox mediator to polysulfides at fast charging rates. We believe that the mechanistic insight generated in this work will be useful to the development of predictive models as well as to the rational design of lithium-sulfur battery components.

\section{Acknowledgments}

The described XAS measurements were carried out at the Stanford Synchrotron Radiation Lightsource, a Directorate of SLAC National Accelerator Laboratory and an Office of Science User Facility operated for the U.S. Department of Energy Office of Science by Stanford University. Use of the Stanford Synchrotron Radiation Lightsource, SLAC National Accelerator Laboratory, is supported by the U.S. Department of Energy, Office of Science, Office of Basic Energy Sciences under Contract No. DE-AC02-76SF00515. The authors also thank the Paul Scherrer Institut, Villigen, Switzerland for provision of synchrotron radiation beamtime at the PHOENIX beamline of the SLS, Dr. T. Huthwelker and Dr. C. Borca for their support during experiments at SLS, Dr. S. Webb for his support during the experiments at SSRL, as well as M. Wetjen and Q. He for helpful discussions. We gratefully acknowledge the funding by the German Federal Ministry for Economic Affairs and Energy (funding number: 03ET6045D). Y. Gorlin gratefully acknowledges the support of the Alexander von Humboldt Postdoctoral Fellowship and Carl Friedrich von Siemens Fellowship Supplement. M. Tromp gratefully acknowledges NWO (NWO-VIDI 723.014.010) and the University of Amsterdam Research Priority Area Sustainable Chemistry.

\section{Appendix A}

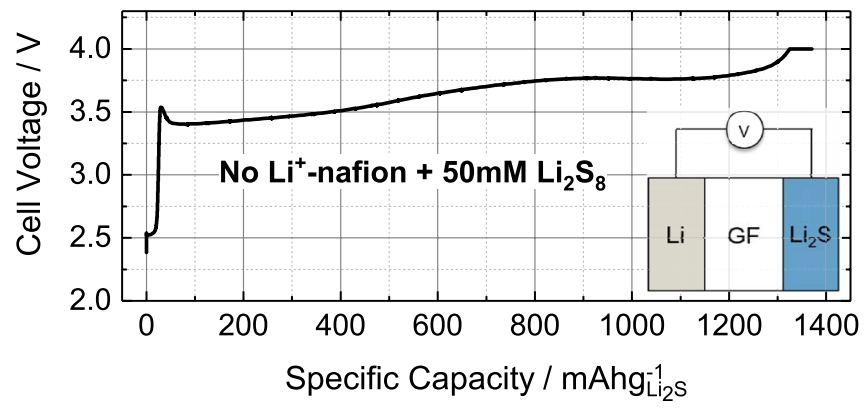

Figure A1. Voltage curve over the specific capacity for the first charge of $\mathrm{Li}_{2} \mathrm{~S}$ at a $\mathrm{C}$-rate of $\mathrm{C} / 2$ without $\mathrm{Li}^{+}$-Nafion interlayer, but with the addition of $50 \mathrm{mM}$ $\mathrm{Li}_{2} \mathrm{~S}_{8}$ (loading $\mathrm{Li}_{2} \mathrm{~S}: 1.5 \mathrm{mg}_{\mathrm{Li} 2 \mathrm{~S}} / \mathrm{cm}^{2}$, electrolyte: $1 \mathrm{M} \mathrm{LiClO}_{4}, 0.5 \mathrm{M} \mathrm{LiNO}_{3}$ in DOL:DME, 1:1 vol:vol). The low overpotential can only be maintained for a short period of time, before the charge continues at a potential above $3.0 \mathrm{~V}$. This result contrasts the equivalent data obtained for the configuration with $\mathrm{Li}^{+}-$Nafion interlayer in Fig. $6 \mathrm{a}$. 


\section{ORCID}

Armin Siebel (10 https://orcid.org/0000-0001-5773-3342

Yelena Gorlin (D) https://orcid.org/0000-0002-9242-8914

\section{References}

1. A. Rosenman, E. Markevich, G. Salitra, D. Aurbach, A. Garsuch, and F. F. Chesneau, Adv. Energ. Mat., 5, 1500212 (2015).

2. O. Gröger, H. A. Gasteiger, and J.-P. Suchsland, J. Electrochem. Soc., 162, A2605 (2015).

3. P. Patel, ACS Cent. Sci., 1, 161 (2015).

4. A. Manthiram, Y. Fu, S. H. Chung, C. Zu, and Y. S. Su, Chem. Rev., 114, 11751 (2014).

5. A. Rapinett, Zephyr: A High Altitude Long Endurance Unmanned Air Vehicle, in Physics Department, University of Surrey (2009).

6. Y. Deng, J. Li, T. Li, X. Gao, and C. Yuan, J. Power Sources, 343, 284 (2017).

7. M. R. Busche, P. Adelhelm, H. Sommer, H. Schneider, K. Leitner, and J. Janek, J. Power Sources, 259, 289 (2014).

8. X.-B. Cheng, J.-Q. Huang, H.-J. Peng, J.-Q. Nie, X.-Y. Liu, Q. Zhang, and F. Wei, J. Power Sources, 253, 263 (2014).

9. Y. V. Mikhaylik and J. R. Akridge, J. Electrochem. Soc., 151, A1969 (2004).

10. J. H. Yom, S. M. Cho, S. W. Hwang, and W. Y. Yoon, J. Electrochem. Soc., 163, A2179 (2016).

11. Z. W. Seh, H. Wang, N. Liu, G. Zheng, W. Li, H. Yao, and Y. Cui, Chem. Sci., 5, 1396 (2014).

12. X. Tao, J. Wang, C. Liu, H. Wang, H. Yao, G. Zheng, Z. W. Seh, Q. Cai, W. Li, G. Zhou, C. Zu, and Y. Cui, Nat. Commun., 7, 11203 (2016).

13. X. Liang, C. Y. Kwok, F. Lodi-Marzano, Q. Pang, M. Cuisinier, H. Huang, C. J. Hart D. Houtarde, K. Kaup, H. Sommer, T. Brezesinski, J. Janek, and L. F. Nazar, Adv. Energ. Mat., 6, 1501636 (2016).

14. F. Wu, S. Thieme, A. Ramanujapuram, E. Zhao, C. Weller, H. Althues, S. Kaskel, O. Borodin, and G. Yushin, Nano Energy, 40, 170 (2017).

15. H. Kim, F. Wu, J. T. Lee, N. Nitta, H.-T. Lin, M. Oschatz, W. I. Cho, S. Kaskel, O. Borodin, and G. Yushin, Adv. Energ. Mat., 5, 1401792 (2015).

16. T. A. Pascal, K. H. Wujcik, J. Velasco-Velez, C. Wu, A. A. Teran, M. Kapilashrami, J. Cabana, J. Guo, M. Salmeron, N. Balsara, and D. Prendergast, J. Phys. Chem. Lett., $\mathbf{5}, 1547$ (2014)

17. M. A. Lowe, J. Gao, and H. D. Abruña, $R S C A d v ., 4$, 18347 (2014).

18. Y. Gorlin, A. Siebel, M. Piana, T. Huthwelker, H. Jha, G. Monsch, F. Kraus, H. A. Gasteiger, and M. Tromp, J. Electrochem. Soc., 162, A1146 (2015).

19. M. Cuisinier, P.-E. Cabelguen, S. Evers, G. He, M. Kolbeck, A. Garsuch, T. Bolin, M. Balasubramanian, and L. F. Nazar, J. Phys. Chem. Lett., 4, 3227 (2013).

20. J. Nelson, S. Misra, Y. Yang, A. Jackson, Y. Liu, H. Wang, H. Dai, J. C. Andrews, Y. Cui, and M. F. Toney, J. Am. Chem. Soc., 134, 6337 (2012).
21. N. A. Cañas, S. Wolf, N. Wagner, and K. A. Friedrich, J. Power Sources, 226, 313 (2013).

22. S. Walus, C. Barchasz, J. F. Colin, J. F. Martin, E. Elkaim, J. C. Lepretre, and F. Alloin, Chem. Commun., 49, 7899 (2013).

23. H. Jha, I. Buchberger, X. Cui, S. Meini, and H. A. Gasteiger, J. Electrochem. Soc., 162, A1829 (2015).

24. Q. Zou and Y. C. Lu, J. Phys. Chem. Lett., 7, 1518 (2016).

25. M. U. Patel, R. Demir-Cakan, M. Morcrette, J. M. Tarascon, M. Gaberscek, and R. Dominko, ChemSusChem, 6, 1177 (2013).

26. C. Shen, J. Xie, M. Zhang, J. P. Zheng, M. Hendrickson, and E. J. Plichta, J. Electrochem. Soc., 164, A1220 (2017).

27. Y.-C. Lu, Q. He, and H. A. Gasteiger, J. Phys. Chem. C, 118, 5733 (2014).

28. C. Barchasz, F. Molton, C. Duboc, J. C. Lepretre, S. Patoux, and F. Alloin, Anal. Chem., 84, 3973 (2012).

29. Q. Wang, J. Zheng, E. Walter, H. Pan, D. Lv, P. Zuo, H. Chen, Z. D. Deng, B. Y. Liaw, X. Yu et al., J. Electrochem. Soc., 162, A474 (2015).

30. M. Wild, L. O'Neill, T. Zhang, R. Purkayastha, G. Minton, M. Marinescu, and G. J. Offer, Energy Environ. Sci., 8, 3477 (2015).

31. M. Marinescu, T. Zhang, and G. J. Offer, Phys. Chem. Chem. Phys., 18, 584 (2016).

32. Y. Gorlin, M. U. M. Patel, A. Freiberg, Q. He, M. Piana, M. Tromp, and H. A. Gasteiger, J. Electrochem. Soc., 163, A930 (2016).

33. Y. Yang, G. Zheng, S. Misra, J. Nelson, M. F. Toney, and Y. Cui, J. Am. Chem. Soc., 134, 15387 (2012).

34. I. Bauer, S. Thieme, J. Brückner, H. Althues, and S. Kaskel, J. Power Sources, 251, 417 (2014).

35. H. Jha and H. A. Gasteiger, DE Pat. No. 102013005082 A1. Munich, Germany: Deutsches Pat. und Markenamt (2014).

36. D. Aurbach, E. Pollak, R. Elazari, G. Salitra, C. S. Kelley, and J. Affinito, J. Electrochem. Soc., 156, A694 (2009).

37. A. T. S. Freiberg, A. Siebel, A. Berger, S. M. Webb, Y. Gorlin, M. Tromp, and H. A. Gasteiger, J. Phys. Chem. C, 122, 5303 (2018).

38. J. M. Durand, J. Olivier-Fourcade, J. C. Jumas, M. Womes, C. M. Teodorescu, A. Elafif, J. M. Esteva, and R. C. Karnatak, J. Phys. B, 29, 5773 (1996).

39. G. Almkvist, K. Boye, and I. Persson, J. Synchrotron. Radiat., 17, 683 (2010).

40. R. D. Rauh, F. S. Shuker, J. M. Marston, and S. B. Brummer, J. Inorg. Nucl. Chem., 39, 1761 (1977).

41. L. Wang, Y. Wang, and Y. Xia, Energy Environ. Sci., 8, 1551 (2015).

42. J. Y. Koh, M.-S. Park, E. H. Kim, B. O. Jeong, S. Kim, K. J. Kim, J.-G. Kim, Y.-J. Kim, and Y. Jung, J. Electrochem. Soc., 161, A2133 (2014).

43. J. Wandt, A. Freiberg, R. Thomas, Y. Gorlin, A. Siebel, R. Jung, H. A. Gasteiger, and M. Tromp, J. Mater. Chem. A, 4, 18300 (2016).

44. M. U. Patel, I. Arcon, G. Aquilanti, L. Stievano, G. Mali, and R. Dominko, ChemPhysChem, 15, 894 (2014).

45. K. Cai, M. K. Song, E. J. Cairns, and Y. Zhang, Nano Lett, 12, 6474 (2012)

46. K. Zhang, L. Wang, Z. Hu, F. Cheng, and J. Chen, Sci Rep, 4, 6467 (2014). 